ORIGINAL ARTICLE

\title{
Acute childhood leukaemia and environmental exposure to potential sources of benzene and other hydrocarbons; a case-control study
}

\author{
C Steffen, M F Auclerc, A Auvrignon, A Baruchel, K Kebaili, A Lambilliotte, G Leverger, \\ D Sommelet, E Vilmer, D Hémon, J Clavel
}

Occup Environ Med 2004;61:773-778. doi: 10.1136/oem.2003.010868

See end of article for authors' affiliations

.....................

Correspondence to: Dr J Clavel, Inserm U170, 16 avenue Paul VaillantCouturier, 94807 Villejuif cedex, France; clavel@ vif.inserm.fr

Accepted 29 January 2004

\begin{abstract}
Aim: To analyse the association between potential environmental exposure to hydrocarbons and the risk of acute childhood leukaemia.

Methods: A hospital based multicentre case control study, stratified on centre, age, and sex, with 280 leukaemia cases and 285 controls was carried out. Data were collected by a standardised interview of the mothers.

Results: No clear association was seen between maternal occupational exposure to hydrocarbons during pregnancy and leukaemia, or between residential traffic density and leukaemia. There was an association between dwellings neighbouring a petrol station or a repair garage during childhood and the risk of childhood leukaemia (OR 4.0,95\% Cl 1.5 to 10.3), with a duration trend. The association, which appeared particularly strong for acute non-lymphocytic leukaemia (OR 7.7, 95\% Cl 1.7 to 34.3), was not altered by adjustment for potential confounding factors.

Conclusions: Results showed an association between acute childhood leukaemia and dwellings neighbouring auto repair garages and petrol stations, which are benzene emitting sources. These findings could be due to chance, although the strength of the association and the duration trend are arguments for a causal association.
\end{abstract}

A cute leukaemia $(\mathrm{AL})$ is the most frequent malignant disease in children, though it fortunately still remains relatively rare, with an incidence rate of 4 in 100000 per year in developed countries. ${ }^{1}$ Only a small number of risk factors related to childhood AL have been identified, namely exposure to high doses of ionising radiation, trisomy 21 , certain rare diseases (Fanconi's anaemia, ataxia-telangiectasia, type 1 neurofibromatosis), and certain chemotherapies.

Epidemiological studies have shown a clear association between occupational exposure to benzene and AL in adults, especially acute non-lymphocytic leukaemia. This association was shown for workers of the rubber industry, where exposure level to benzene used to be very high in the past. ${ }^{23}$

However, direct implication of exposure to benzene in childhood leukaemia has never been reported. In fact, environmental exposure levels, which children might be exposed to, are very low compared to those of the historic cohort of rubber workers. ${ }^{2}$

The goal of the present study was to determine the role played by exposure to certain hydrocarbons in the risk of childhood leukaemia. Hence, the review of literature focused on two different kinds of children's potential exposure to hydrocarbons: in utero exposure through maternal occupational exposure to hydrocarbons, and in utero or childhood exposure to environmental hydrocarbons.

We identified seven case-control studies dealing with maternal occupational exposure to hydrocarbons during pregnancy and childhood leukaemia. ${ }^{4-10}$ Five reported a positive association between occupational exposure to different hydrocarbons and $\mathrm{AL}^{,-10}$ although the association was statistically significant in only three of the studies. ${ }^{7810}$ The association was particularly strong for benzene and nonlymphocytic acute leukaemia.
Different kinds of geographical studies have been carried out to determine the relation between children's dwellings in the neighbourhood of certain potential hydrocarbon pollution sources (for example, oil refineries, petrol tanks and stations) and AL. ${ }^{11-16}$ Knox found that clusters of cases were significantly closer to oil refineries or depots than controls. ${ }^{12}$ Reynolds et al showed a statistically significant association between a hazardous air pollutants exposure score and childhood leukaemia. ${ }^{17}$

Five case-control studies as well as one geographical study focused on the role of exposure to automobile emissions and childhood AL. ${ }^{11}{ }^{18-23}$ Four of the six studies showed a positive association between different indicators of air pollution or heavy traffic in the vicinity of children's dwellings and AL. Two of them were statistically significant. ${ }^{19} 2022$

In the present study we analysed the relation between acute childhood leukaemia and repair garages, petrol stations, high traffic roads in the proximity of children's dwellings, as well as maternal occupational exposure to hydrocarbons during pregnancy. This paper is based on a case-control study investigating potential environmental and genetic leukaemia risk factors.

\section{SUBJECTS AND METHODS Subjects}

The study was a multicentre hospital based case-control study, which has been described elsewhere. ${ }^{24-26}$ The hospital based design was chosen since case and control blood samples were required, with the approval from an ethics committee. Cases were identified from hospitals of four

Abbreviations: AL, acute leukaemia; ALL, acute lymphocytic leukaemia; ANLL, acute non-lymphocytic leukaemia 
centres: Nancy, Lille, Lyon, and Paris. To be eligible for the study, children aged 0-14 years at the time of diagnosis had to be newly diagnosed with acute leukaemia (AL) between 1 January 1995 and 31 December 1999. Acute leukaemia cases occurring after chemotherapy were excluded. Diagnosis was based on cytology and immunophenotype. The cases and controls were frequency matched on sex, age, centre, and ethnic origin. In each centre, the same interviewer was responsible for the inclusion of both cases and controls and for the local frequency matching on age and sex. All the mothers of eligible cases or controls who were present during the interviewers' working hours were asked for participating in the study. Controls were recruited in the same hospitals as cases among children aged less than 15 years, living in the same area as cases, and hospitalised for acute pathologies, mainly traumatic $(51 \%)$ and non-traumatic (34\%) orthopaedic diseases. Many different diagnostic categories were included in order to avoid selection biases in the event that a particular disease was related to the exposures of interest. However, children hospitalised for cancer or a major congenital malformation were not eligible for the study, since those diseases may share risk factors with leukaemia. The oncology departments recruit patients from more distant places than do control departments, and this could have introduced bias. In order to keep cases and controls comparable in terms of socioeconomic category and rural/ urban status, only children living in the same administrative region as the hospital location were included in the study.

Among the mothers of the 282 eligible cases, two mothers refused to participate. Thus, 280 acute leukaemia cases were included in the study. Among them, 40 were diagnosed with acute non-lymphocytic leukaemia (ANLL), comprising $4 \mathrm{MO}$, $10 \mathrm{Ml}-\mathrm{M} 2$, and $18 \mathrm{M} 4-\mathrm{M} 5$ morphological types, and 240 with acute lymphocytic leukaemia (ALL).

Among the 291 eligible controls, four were excluded-one because the child was adopted and the three others because their mothers decided to stop the interview before the questionnaire on residential history was completed. Two control mothers refused to participate.

\section{Data collection}

Data were collected by specifically trained medical doctors through a face-to-face interview of the mothers of the children (cases and controls), after having given written informed consent. The interview of the case mothers was conducted during the first remission period of the disease (on average, two months after diagnosis and beginning of treatment). Case and control mothers were interviewed under strictly similar conditions, at the same period, using a standardised questionnaire.

For all children, a history of exposure to hydrocarbons at each of their different dwelling places was taken. The period investigated spanned from date of conception to date of diagnosis or interview (controls). In utero exposure and childhood exposure were considered separately. Among the different types of exposure investigated was the existence of a neighbouring business, and especially an automobile repair garage or a petrol station.

By "neighbouring business" was meant a property adjoining the child's dwelling. Questions were also asked to determine the possible exposure to heavy traffic roads in the vicinity ( $<50$ metres) of the children's homes. The questionnaire also included questions on parental occupations, which were coded using international codes for job titles and industrial activities. For the categorisation of jobs with respect to potential exposure to benzene and other solvents, we used a basic job-exposure matrix we had developed with industrial hygienists for previous studies. ${ }^{28}$ A checklist of closed questions on mothers' tasks during their pregnancy was also included in the questionnaire, with explicit items on solvent exposure.

\section{Methods}

Odds ratios (ORs) were calculated by unconditional logistic regression (SAS software package), including matching variables age, sex, centre, and ethnic origin. We calculated 95\% confidence intervals (CI) for all odds ratios. Minimal detectable odds ratios for a study of 280 cases and 280 controls, with a statistical power of $80 \%($ alpha $=0.05)$ were 1.6 and 2.2 respectively for a $30 \%$ and a $5 \%$ frequency for a given exposure in the control group.

\section{RESULTS}

No difference was observed between cases and controls on the matching variables sex, origin, and centre (table 1). Sixty per cent of the cases were 2-6 years old, whereas only $45 \%$ of the controls were in that age group. This was due to the difficulty of recruiting enough controls $2-3$ years old, which corresponds to the age of the peak incidence of AL.

We found no significant difference between cases and controls regarding socioeconomic status and level of education of the parents, family situation, or urban and rural dwelling status.

\section{Exposure to a neighbouring repair garage or petrol station}

Positive associations were observed between AL and exposure to a close neighbouring repair garage or petrol station for both periods: in utero and childhood (table 2). The association was statistically significant for the latter period (OR 4.0 95\% CI 1.5 to 10.3 ).

The odds ratios for the subgroups of ANLL and ALL were respectively 7.7 (95\% CI 1.7 to 34.3 ) and 3.6 (95\% CI 1.3 to 9.9) for exposure during childhood (table 3 ).

Exposures to petrol stations during intrauterine life and during childhood were strongly associated. Although confidence intervals were large, the association between exposure to a petrol station and AL appeared to be stronger when it spanned over the childhood period only (five cases and one control, OR 9.3, 95\% CI 1.0 to 88.4 ) rather than over the in utero period only (one case and two controls). An OR of 3.1 (95\% CI 1.0 to 8.9 ) was associated with exposure in utero and during childhood ( 12 cases and six controls).

A positive, statistically significant trend (OR 1.03, 95\% CI 1.01 to 1.05 , per month of exposure) was found between duration of childhood exposure to a neighbouring repair garage or petrol station and AL (table 4).

The association remained statistically significant (OR 3.4, 95\% CI 1.3 to 9.1 ) when only those children were classified as exposed, whose exposure started at least one year prior to AL diagnosis or interview (controls), though, in that case, the duration trend was no longer consistent.

A sensitivity analysis on the potential impact of the missing values concerning exposure to petrol stations or repair garages was carried out. In the case that all missing values stemmed either from exposed children only or from unexposed children only, the odds ratios would remain statistically significant: respectively OR 2.3 (95\% CI 1.1 to 4.6) and OR 3.8 (95\% CI 1.5 to 9.9). In the case that all missing values in cases stemmed from unexposed children and all missing values in controls stemmed from exposed children, the odds ratio would be 1.5 (95\% CI 0.7 to 3.1 ).

Unlike for neighbouring garages, no association was found between $\mathrm{AL}$ and other close neighbouring businesses, which included: aluminium, plastic, wood and metalwork, horticulture, processing laboratory (photography), printing plant, bakery, textile and ceramics making, slaughterhouse, retail (paints, mirrors, electric supply), transportation, and service 


\begin{tabular}{|c|c|c|c|c|c|}
\hline & \multicolumn{2}{|c|}{ Cases $(n=280)$} & \multicolumn{2}{|c|}{ Controls ( $n=285$ ) } & \multirow[b]{2}{*}{$\mathbf{p}$} \\
\hline & No. & $\%$ & No. & $\%$ & \\
\hline \multicolumn{6}{|l|}{ Sex } \\
\hline Male & 166 & 59.3 & 166 & 58.3 & NS \\
\hline \multicolumn{6}{|l|}{$\operatorname{Age}^{*}(y)$} \\
\hline$<2$ & 33 & 11.8 & 51 & 17.8 & \\
\hline $2-3$ & 85 & 30.4 & 52 & 18.3 & \\
\hline $4-6$ & 83 & 29.6 & 78 & 27.4 & \\
\hline $7-10$ & 41 & 14.6 & 63 & 22.1 & \\
\hline$\geqslant 11$ & 38 & 13.6 & 41 & 14.4 & $<0.01$ \\
\hline \multicolumn{6}{|l|}{ Centre* } \\
\hline Lille & 39 & 13.9 & 26 & 9.1 & \\
\hline Lyon & 36 & 12.9 & 35 & 12.3 & \\
\hline Nancy & 23 & 8.2 & 22 & 7.7 & \\
\hline Paris & 182 & 65.0 & 202 & 70.9 & NS \\
\hline \multicolumn{6}{|l|}{ Origin* } \\
\hline European & 244 & 87.1 & 236 & 82.8 & \\
\hline North African & 15 & 5.4 & 23 & 8.1 & \\
\hline Other & 21 & 7.5 & 26 & 9.1 & NS \\
\hline \multicolumn{6}{|l|}{ Socioeconomic status } \\
\hline High & 147 & 52.5 & 160 & 55.1 & \\
\hline Intermediate & 55 & 19.6 & 49 & 17.2 & \\
\hline Low & 78 & 27.9 & 75 & 26.3 & NS \\
\hline Missing value & 0 & 0.0 & 1 & 0.4 & \\
\hline \multicolumn{6}{|l|}{ Education of mother } \\
\hline$>$ High school & 90 & 32.1 & 108 & 37.9 & \\
\hline$\leqslant$ High school & 190 & 67.9 & 175 & 61.4 & NS \\
\hline Missing value & 0 & 0.0 & 2 & 0.7 & \\
\hline \multicolumn{6}{|l|}{ Education of father } \\
\hline$>$ High school & 87 & 31.1 & 99 & 34.7 & \\
\hline$\leqslant$ High school & 181 & 64.6 & 170 & 59.7 & NS \\
\hline Missing value & 12 & 4.3 & 16 & 5.6 & \\
\hline \multicolumn{6}{|l|}{ Family situation } \\
\hline Couple & 247 & 88.2 & 242 & 84.9 & \\
\hline Widow/separate & 26 & 9.3 & 35 & 12.3 & \\
\hline Single & 7 & 2.5 & 5 & 1.8 & NS \\
\hline Missing values & 0 & 0.0 & 3 & 1.1 & \\
\hline \multicolumn{6}{|l|}{ Type of dwelling } \\
\hline Urban & 221 & 78.9 & 234 & 82.1 & \\
\hline Rural & 58 & 20.7 & 49 & 17.2 & NS \\
\hline Missing value & 1 & 0.4 & 2 & 0.7 & \\
\hline
\end{tabular}

corporations. The number of different businesses was 1 or 2 for each business type.

\section{Exposure to high traffic roads}

No association was found between the existence of high traffic roads within a 50 metre distance of the children's homes and $\mathrm{AL}$, neither during the in utero period nor during the childhood period (table 5). Adjusting for rural or urban location did not have any influence on the risk estimates.
Adjustment for potential confounders previously identified, ${ }^{24-26}$ such as family history of solid tumour or haematological neoplasm, early common infection, day care attendance, and breast feeding, and for high traffic roads did not modify the association between exposure to garages and AL.

\section{Maternal occupational exposure to hydrocarbons during pregnancy}

No case or control mother worked in a laboratory or industry with exposure to benzene. Two control mothers and no case

\begin{tabular}{|c|c|c|c|c|c|c|}
\hline & \multicolumn{2}{|c|}{ Cases $(n=280)$} & \multicolumn{2}{|c|}{ Controls $(n=285$ ) } & \multirow[b]{2}{*}{ OR } & \multirow[b]{2}{*}[95\%\mathrm{Cl}]{} \\
\hline & No. & $\%$ & No. & $\%$ & & \\
\hline \multicolumn{7}{|l|}{ In utero period } \\
\hline No neighbouring business & 257 & 91.8 & 256 & 89.8 & 1.0 & (ref.) \\
\hline Repair garage or petrol station* & 13 & 4.7 & 8 & 2.8 & 2.2 & (0.9 to 5.7$)$ \\
\hline Other neighbouring business & 6 & 2.1 & 9 & 3.2 & 0.8 & (0.3 to 2.4 ) \\
\hline Missing values & 4 & 1.4 & 12 & 4.9 & & \\
\hline \multicolumn{7}{|l|}{ Childhood period } \\
\hline No neighbouring business & 249 & 88.9 & 258 & 90.5 & 1.0 & (ref.) \\
\hline Repair garage or petrol station* & 17 & 6.1 & 7 & 2.5 & 4.0 & (1.5 to 10.3$)$ \\
\hline Other neighbouring business & 8 & 2.9 & 8 & 2.8 & 1.4 & (0.5 to 4.1$)$ \\
\hline Missing values & 6 & 2.1 & 12 & 4.2 & & \\
\hline
\end{tabular}




\begin{tabular}{|c|c|c|c|c|c|c|}
\hline & \multicolumn{2}{|c|}{ Cases $(n=280)$} & \multicolumn{2}{|c|}{ Controls $(n=285)$} & \multirow[b]{2}{*}{ OR } & \multirow[b]{2}{*}{$(95 \% \mathrm{Cl})$} \\
\hline & No. & $\%$ & No. & $\%$ & & \\
\hline Acute non-lymphocytic leukaemia & $(n=40)$ & & & & & \\
\hline No neighbouring business & 35 & 87.5 & 258 & 90.5 & 1.0 & (ref.) \\
\hline Repair garage or petrol station* & 4 & 10.0 & 7 & 2.5 & 7.7 & (1.7 to 34.3 ) \\
\hline Other neighbouring business & 1 & 2.9 & 8 & 2.8 & 1.0 & $(0.1$ to 8.9$)$ \\
\hline Missing values & 0 & 0 & 12 & 4.2 & & \\
\hline Acute lymphocytic leukaemia & $(n=240)$ & & & & & \\
\hline No neighbouring business & 214 & 89.2 & 258 & 90.5 & 1.0 & (ref.) \\
\hline Repair garage or petrol station* & 13 & 5.4 & 7 & 2.5 & 3.6 & (1.3 to 9.9$)$ \\
\hline Other neighbouring business & 7 & 2.9 & 8 & 2.8 & 1.5 & $(0.5$ to 4.6$)$ \\
\hline Missing values & 6 & 2.5 & 12 & 4.2 & & \\
\hline
\end{tabular}

*With or without another business.

mothers were employed as petrol station cashiers. Only very few mothers declared having been exposed to glues, paints, or varnishes containing organic solvents (seven cases and four controls, OR 1.7, 95\% CI 0.5 to 60 ).

\section{DISCUSSION}

An association between a history of childhood dwelling next to a repair garage or petrol station and childhood leukaemia was observed.

Selection of cases and controls did not depend directly on the type of neighbourhood of the dwellings. Therefore, a selection bias on the neighbouring garage variable would only have been introduced, if it were related to another factor that might itself have influenced inclusion and exclusion of cases and controls, such as parental socioeconomic status or academic level. In the present study, no statistically significant difference concerning these variables was found between cases and controls. Furthermore, the neighbouring garage variable was not associated with these sociodemographic factors. The hospital based design of the study was chosen since case and control blood samples were required. Special care was therefore paid to selecting an appropriate control group. Controls were included from many diagnostic categories, none of those categories being related to the variables of interest. In a recent paper, Infante-Rivard analysed the possibility of differential reporting of exposures in a case-control study on childhood leukaemia using either hospital or population controls. ${ }^{29}$ Both control groups appeared comparable according to socioeconomic characteristics, and evidencing no systematic reporting bias, although the odds ratio tended to be more often closer to 1 with hospital controls. This observation suggests that the present findings are unlikely to be attributable to the hospital based design of our study.
Over-declaration by the cases' mothers of risk factors, which they might deem possibly related to the disease of their children, cannot be excluded. This could introduce a differential error of classification and thus create a false statistical association between these risk factors and AL.

The question about the presence of a neighbouring garage or petrol station next to the index child's house was quite unambiguous, which should have limited over- or underdeclaration. Moreover, for other variables, which might also be considered as risk factors and therefore susceptible to the same type of misclassification, no association with AL was found (for example, neighbouring businesses other than garages and petrol stations, high traffic roads). Finally, there is no particular public concern about a potential relation between repair garages or petrol stations and leukaemia.

Classification of missing values is also susceptible to introduce errors. A sensitivity analysis of the impact of these missing values on the estimated odds ratios was carried out. It showed that odds ratios always remained greater than 1 (between 1.5 and 4) and that loss of the statistically significant association would only occur for a very unlikely distribution of garage exposure between cases and controls among these missing values.

Confounders might have influenced our findings. We therefore introduced a variety of possible confounding factors in our model in order to test the consistency of the association between neighbouring garages and AL. Among them were variables previously identified as related to AL (family history of solid tumour or haematological neoplasm, early common infections, and day-care attendance ${ }^{25} 26$ ). We also introduced simultaneously the variables related to neighbouring garages and petrol stations, and proximity of high traffic roads. Adjusting for these factors did not alter the results.

\begin{tabular}{|c|c|c|c|c|c|c|}
\hline & \multicolumn{2}{|c|}{ Cases $(n=280)$} & \multicolumn{2}{|c|}{ Controls ( $n=285$ ) } & \multirow[b]{2}{*}{ OR } & \multirow[b]{2}{*}{$(95 \% \mathrm{Cl})$} \\
\hline & No. & $\%$ & No. & $\%$ & & \\
\hline \multicolumn{7}{|c|}{$\begin{array}{l}\text { Exposure duration to neighbouring } \\
\text { petrol station or repair garage }\end{array}$} \\
\hline 0 & 257 & 91.8 & 268 & 94.0 & 1.0 & (ref.) \\
\hline $1-35$ months & 8 & 2.9 & 4 & 1.4 & 3.4 & $(0.9$ to 12.4$)$ \\
\hline$\geqslant 36$ months & 9 & 3.2 & 3 & 1.1 & 4.7 & $(1.2$ to 18.5$)$ \\
\hline Missing values & 6 & 2.1 & 10 & 3.5 & & \\
\hline OR per month of exposure & & & & & $\begin{array}{l}1.03 \\
\text { lp trer }\end{array}$ & $\begin{array}{l}(1.01 \text { to } 1.05) \\
0.05)\end{array}$ \\
\hline
\end{tabular}


Table 5 Childhood acute leukaemia and exposure to high traffic roads $(<50 \mathrm{~m})$ according to exposure period

\begin{tabular}{|c|c|c|c|c|c|c|c|c|c|c|c|c|}
\hline & \multicolumn{6}{|c|}{ In utero exposure } & \multicolumn{6}{|c|}{ Childhood exposure } \\
\hline & \multicolumn{2}{|c|}{ Cases $(n=280)$} & \multicolumn{2}{|c|}{ Controls ( $n=285$ ) } & \multirow[b]{2}{*}{ OR } & \multirow[b]{2}{*}{$(95 \% \mathrm{Cl})$} & \multicolumn{2}{|c|}{ Cases $(n=280)$} & \multicolumn{2}{|c|}{ Controls $(n=285$ ) } & \multirow[b]{2}{*}{ OR } & \multirow[b]{2}{*}{$(95 \% \mathrm{Cl})$} \\
\hline & No. & $\%$ & No. & $\%$ & & & No. & $\%$ & No. & $\%$ & & \\
\hline \multicolumn{13}{|l|}{ Heavy traffic road } \\
\hline All road types & 134 & 47.9 & 149 & 52.3 & 0.9 & $(0.7$ to 1.3$)$ & 155 & 55.4 & 164 & 57.5 & 1.1 & $(0.8$ to 1.6$)$ \\
\hline $\begin{array}{l}\text { Secondary road or main } \\
\text { street }\end{array}$ & 98 & 35.0 & 104 & 36.5 & 1.0 & $(0.7$ to 1.4$)$ & 114 & 40.7 & 124 & 43.5 & 1.1 & $(0.7$ to 1.6$)$ \\
\hline Primary road & 19 & 6.8 & 21 & 7.4 & 0.8 & $(0.4$ to 1.6$)$ & 28 & 10.0 & 21 & 7.3 & 1.1 & $(0.6$ to 2.2$)$ \\
\hline Motorway or similar road & d 11 & 3.9 & 13 & 4.6 & 1.3 & $(0.5$ to 3.2$)$ & 14 & 5.0 & 17 & 6.0 & 1.3 & $(0.6$ to 2.9$)$ \\
\hline
\end{tabular}

Although exposure to neighbouring garages and petrol stations concerned only a small number of children, we observed a positive, statistically significant duration trend (OR 1.4 per year of exposure, p for trend $<0.05$ ).

Benzene exposure has been studied in occupational medicine (rubber industry, Pliofilm cohort) and is now an established cause of AL in adults, especially ANLL. It has therefore been classified in group 1 (carcinogenic substances) by IARC. ${ }^{27}{ }^{30}$ Unleaded fuel, which is very largely distributed, contains small amounts of benzene. Moreover, the benzene concentration in air around petrol stations during refuelling may be relatively high compared to the environmental background concentration. ${ }^{2}$

As far as we know, exposure to neighbouring auto-repair garages and petrol stations, in relation to acute childhood leukaemia, has never been analysed in a case-control study. The few studies in the literature concerning $\mathrm{AL}$ and residential exposure to hydrocarbons are geographical studies that deal with a variety of hydrocarbon emitting sources (oil refineries, tanks and petrol stations). ${ }^{11-16}$ In these studies, the distance between pollution sources and dwellings has been determined by geographical means and ranges from 100 to 7500 metres. Adjoining sources have not been studied specifically. Harrison et al found a non-statistically significant association between children living in a 100 metre range of a petrol station and AL (OR 1.99, 95\% CI 0.73 to 5.43). ${ }^{11}$ Because of a very different methodology, the results of these studies cannot be easily compared with the findings of our case-control study.

Rinsky et al used data from the Pliofilm cohort study to construct a dose-response relation for adult workers between cumulative exposure to benzene and risk of AL. ${ }^{31}$

According to that equation, to obtain an odds ratio of 4 , a five year exposure to an air concentration of $77 \mathrm{mg} / \mathrm{m}^{3}$ of benzene would be necessary ( 24 hours-a-day, 7 days-a-week exposure). This is an extremely high concentration, which might only have been observed in the rubber industry, prior to enforcement of more stringent regulations. Environmental background concentration is around $4 \mu \mathrm{g} / \mathrm{m}^{3}, 2$ and during refuelling, air peak concentration, very close to the pump, may reach $1-10 \mathrm{mg} / \mathrm{m}^{3}$. Therefore, if the observed association reflected a causal relation, children's sensitivity to benzene regarding the risk of developing AL would be much higher than adults'. This hypothesis needs to be confirmed by further investigations. In particular, the possible involvement of other substances emitted by petrol stations cannot be excluded.

In the present study several independent aetiological hypotheses were tested, including questions about family cancer history, early childhood infections, day care attendance, breast feeding, and potential environmental exposure to hydrocarbons. Thus, many statistical tests were carried out and some of them may have been statistically significant by mere chance. Concerning the neighbouring garages, the strength and the specificity of the association, the duration trend, and the plausibility are arguments against a random association.

Unlike for the exposure to neighbouring petrol stations, our results did not confirm the findings of certain studies, which showed an association between maternal occupational exposure during pregnancy to hydrocarbons and $\mathrm{AL}^{7{ }^{7}}$ or between high traffic roads in the vicinity of children's dwellings and AL. ${ }^{20} 22$ A limit of our results concerning roads was that the exposure was self declared and that distance to the roads is probably collected approximately. Since no objective criterion of the actual local air pollution or the traffic density was available, it is possible that the highest exposure group was diluted in the lower exposure groups. Concerning occupational exposure during pregnancy to hydrocarbons, the number of exposed mothers was very small. Undeclared occupational exposures are possible, but would probably not have concerned benzene.

\section{Conclusion}

The present study showed an association between childhood $\mathrm{AL}$ and dwellings neighbouring auto-repair garages and petrol stations, which possibly expose children to benzene. These findings have, as far as we know, never been described before, and could be due to chance. However, the strength of the association and the duration trend are arguments for a causal association. These results need to be confirmed by further investigations. Hence, future epidemiological studies on acute childhood leukaemia, assessing specifically exposure to the most common hazardous substances emitted by petrol stations and garages, and especially benzene, would be useful.

\section{ACKNOWLEDGEMENTS}

This work was supported by grants from INSERM, the French Ministère de l'Environnement et de l'Aménagement du Territoire, the Association pour la Recherche contre le Cancer, the Fondation de France, the Fondation Jeanne Liot, the Fondation WeisbremBenenson, the Ligue Contre le Cancer du Val de Marne, and the Ligue Nationale Contre le Cancer.

We are grateful to Diane Farkas, Martine Zagouri, and Naïma Belkacem, who contributed to the interviews, and to Martine Valdes, Isabelle Jaussent, Laurence Mandereau, and Dominique Ridondelli, for technical assistance. We also thank the heads of the departments who helped us to include their patients as controls: Profs Bensahel, Bérard, Carlioz, Deberigny, Felipe, Herbault, Lascombes, Pouliquen, and Rigault.

\section{Authors' affiliations}

C Steffen, D Hémon, J Clavel, French National Institute of Health and Medical Research, INSERM U170, Villejuif, France

M F Auclerc, A Baruchel, Department of Pediatric Hematology, SaintLovis Hospital, Paris, France

A Auvrignon, G Leverger, Department of Pediatric Hematology, Armand Trousseau Hospital, Paris, France

K Kebaili, Department of Pediatric Hematology, Debrousse Hospital, Lyon, France 
A Lambilliotte, Department of Pediatric Hematology-Oncology, Jeanne de Flandre Hospital, Lille, France

D Sommelet, Department of Pediatric Hematology, Brabois Hospital, Nancy, France

E Vilmer, Department of Pediatric Hematology-Immunology, Robert Debré Hospital, Paris, France

\section{REFERENCES}

1 Little J. Epidemiology of childhood cancer. Lyon: International Agency for Research on Cancer, 1999.

2 Duarte-Davidson R, Courage C, Rushton L, et al. Benzene in the environment: an assessment of the potential risks to the health of the population. Occup Environ Med 2001;58:2-13.

3 Paustenbach DJ, Price PS, Ollison W, et al. Reevaluation of benzene exposure for the Pliofilm (rubberworker) cohort (1936-1976). J Toxicol Environ Health 1992;36:177-231.

4 Buckley JD, Robison LL, Swotinsky R, et al. Occupational exposures of parents of children with acute nonlymphocytic leukemia: a report from the Children's Cancer Study Group. Cancer Res 1989;49:4030-7.

5 Infante-Rivard C, Mur P, Armstrong B, et al. Acute lymphoblastic leukaemia among Spanish children and mothers' occupation: a case-control study. J Epidemiol Community Health 1991;45:11-15.

6 McKinney PA, Alexander FE, Cartwright RA, et al. Parental occupations of children with leukaemia in west Cumbria, north Humberside, and Gateshead. BMJ 1991;302:681-7.

7 Shu XO, Gao YT, Brinton LA, et al. A population-based case-control study of childhood leukemia in Shanghai. Cancer 1988;62:635-44.

8 van Duijn CM, van Steensel-Moll HA, Coebergh JW, et al. Risk factors for childhood acute non-lymphocytic leukemia: an association with maternal alcohol consumption during pregnancy? Cancer Epidemiol Biomarkers Prev 1994;3:457-60.

9 van Steensel-Moll HA, Valkenburg HA, van Zanen GE. Childhood leukemia and parental occupation. A register-based case-control study. Am J Epidemiol 1985:121:216-24.

10 Shu XO, Stewart $P, W e n W Q$, et al. Parental occupational exposure to hydrocarbons and risk of acute lymphocytic leukemia in offspring. Cancer Epidemiol Biomarkers Prev 1999;8:783-91

11 Harrison RM, Leung PL, Somervaille L, et al. Analysis of incidence of childhood cancer in the West Midlands of the United Kingdom in relation to proximity to main roads and petrol stations. Occup Environ Med 1999;56:774-80

12 Knox EG. Leukaemia clusters in childhood: geographical analysis in Britain J Epidemiol Community Health 1994;48:369-76.
13 Knox EG, Gilman EA. Hazard proximities of childhood cancers in Grea Britain from 1953-80. J Epidemiol Community Health 1997;51:151-9.

14 Lyons RA, Monaghan SP, Heaven M, et al. Incidence of leukaemia and lymphoma in young people in the vicinity of the petrochemical plant at Baglan Bay, South Wales, 1974 to 1991. Occup Environ Med 1995;52:225-8.

15 Sans S, Elliott P, Kleinschmidt I, et al. Cancer incidence and mortality near the Baglan Bay petrochemical works, South Wales. Occup Environ Med 1995;52:217-24.

16 Wilkinson $\mathbf{P}$, Thakrar B, Walls $\mathrm{P}$, et al. Lymphohaematopoietic malignancy around all industrial complexes that include major oil refineries in Great Britain. Occup Environ Med 1999;56:577-80.

17 Reynolds P, Von Behren J, Gunier RB, et al. Childhood cancer incidence rates and hazardous air pollutants in California: an exploratory analysis. Environ Health Perspect 2003;111:663-8.

18 Feychting M, Svensson D, Ahlbom A. Exposure to motor vehicle exhaust and childhood cancer. Scand J Work Environ Health 1998;24:8-11.

19 Nordlinder R, Jarvholm B. Environmental exposure to gasoline and leukemia in children and young adults - an ecology study. Int Arch Occup Environ Health 1997;70:57-60.

20 Pearson RL, Wachtel H, Ebi KL. Distance-weighted traffic density in proximity to a home is a risk factor for leukemia and other childhood cancers. J Air Waste Manag Assoc 2000;50:175-80.

21 Raaschou-Nielsen $\mathrm{O}$, Hertel O, Thomsen BL, et al. Air pollution from traffic at the residence of children with cancer. Am J Epidemiol 2001;153:433-43.

22 Savitz DA, Feingold L. Association of childhood cancer with residential traffic density. Scand J Work Environ Health 1989:15:360-3.

23 Langholz B, Ebi KL, Thomas DC, et al. Traffic density and the risk of childhood leukemia in a Los Angeles case-control study. Ann Epidemiol 2002;12:482-7.

24 Perillat-Menegaux F, Clavel J, Auclerc MF, et al. Family history of autoimmune thyroid disease and childhood acute leukemia. Cancer Epidemiol Biomarkers Prev 2003;12:60-3.

25 Perrillat F, Clavel J, Auclerc MF, et al. Day-care, early common infections and childhood acute leukaemia: a multicentre French case-control study. Br J Cancer 2002;86:1064-9.

26 Perrillat F, Clavel J, Jaussent I, et al. Family cancer history and risk of childhood acute leukemia (France). Cancer Causes Control 2001;12:935-41.

27 IARC. Some industrial chemicals and dyestuffs. Lyon: IARC, 1982

28 Clavel J, Glass DC, Cordier S, et al. Standardisation in the retrospective evaluation by experts of occupational exposure to organic solvents in a population based case-control study. Int J Epidemiol 1993;22:S121-6.

29 Infante-Rivard C. Hospital or population controls for case-control studies of severe childhood diseases? Am J Epidemiol 2003;157:176-82.

30 IARC. Overall evaluations of carcinogenicity: an updating of IARC monographs. Volumes 1 to 42 . Lyon: IARC, 1987

31 Rinsky RA. Benzene and leukemia: an epidemiologic risk assessment. Environ Health Perspect 1989;82:189-91. 